\title{
Toward a Psychological Science for a Cultural Species
}

\author{
Steven J. Heine and Ara Norenzayan \\ University of British Columbia, Vancouver, British Columbia, Canada
}

\begin{abstract}
Humans are a cultural species, and the study of human psychology benefits from attention to cultural influences. Cultural psychology's contributions to psychological science can largely be divided according to the two different stages of scientific inquiry. Stage 1 research seeks cultural differences and establishes the boundaries of psychological phenomena. Stage 2 research seeks underlying mechanisms of those cultural differences. The literatures regarding these two distinct stages are reviewed, and various methods for conducting Stage 2 research are discussed. The implications of culture-blind and multicultural psychologies for society and intergroup relations are also discussed.
\end{abstract}

Before we inquire into origins and functional relations, it is necessary to know the thing we are trying to explain.

(Asch, 1952/1987, p. 65)

Humans are a cultural species. Cultural learning, or the ability to acquire behaviors from other individuals, is evident in a variety of different species (Lefebvre \& Giraldeau, 1994; Rendell \& Whitehead, 2001; Whiten et al., 1999). However, humans are unique in the extent to which cultural learning accumulates rapidly over generations, radically alters the ecology in which humans live, and pervades their full repertoire of thoughts and behaviors (Richerson \& Boyd, 2005; Tomasello, 1999). Therefore, a rich understanding of how humans' minds operate would be facilitated by a psychological science that is able to study how specific cultural experiences shape and express universal biological potentials.

Few people would dispute that culture is relevant to psychology. Yet for much of the history of their field, most psychologists have sought to discover and explain human thought and behavior in terms of universal principles that are applicable

Address correspondence to Steven J. Heine or Ara Norenzayan, Department of Psychology, 2136 West Mall, University of British Columbia, Vancouver, BC, V6T 1Z4 Canada, e-mail: heine@psych. ubc.ca or ara@psych.ubc.ca. to all people (at least all non-brain-damaged adults without clinical disorders) regardless of the cultural and historical contexts in which their minds develop and operate. Granted, assumptions of universality are sometimes empirically examined in developmental research and in gender comparisons that attempt to disentangle effects of innate structures and maturation from those of experience or socialization. But it has been the primary goal of cultural psychology to transform this assumption of universality into an empirically testable hypothesis. Cultural psychology, and cross-cultural comparisons more broadly, has enjoyed tremendous growth over the past two decades, and has moved from the margins of psychology to the central theories and findings of the field.

Clearly, there are many possible ways one can approach a project as ambitious and complex as the study of how psychological patterns are manifested across cultures, and even within cultural psychology there are different views and lively debates. Here we offer our own view of the field. The centrality of crosscultural comparisons to progress in all areas of psychology is discussed, and recent advances in cross-cultural research are outlined. We consider some outstanding issues and critiques and recommend avenues for future research. A central theme in our article is that cultural psychology, as is the case with any other scientific field, advances in two overlapping but distinct stages of inquiry. Each stage has its own logic and priorities, an issue to which we now turn.

\section{TWO STAGES OF SCIENTIFIC INQUIRY}

Most scientific inquiry proceeds through two stages. In the first stage, new theories that facilitate the observation and discovery of interesting phenomena are proposed, and various methodological confounds are ruled out. In the second stage, the inner workings of phenomena are more precisely explained, and underlying mechanisms are identified. The first stage continues while the second is under way, because scientific explanations critically depend on the expansion of the database to novel domains and the discovery of additional phenomena. Philosophers and historians of science, although disagreeing about the extent of the role of a priori theories in guiding observation, say that most sciences seem to mature in 
this sequence (Hempel, 1965; Salmon, 1984). Consider Darwin's theory of evolution by natural selection. Darwin developed his theory of natural selection and embarked on decades of systematic cross-species observations and meticulous documentation of features of various organisms and the ecological peculiarities of their habitats (Darwin, 1859/1958). His theory hinged critically on the idea that biological properties are inherited, yet the mechanisms of inheritance were unknown at the time, and his proposal for how inheritance worked was ultimately flawed. One of Darwin's influential critics, Fleeming Jenkin, correctly pointed out that if inheritance were the result of taking the average of the features from the parental contributions, as Darwin proposed, then in each generational transmission, variation would be cut in half. In a few generations, there would be little variation left for inheritance, and natural selection would falter (Boyd \& Silk, 2003). Only decades later was it understood that parental genes remain discrete entities in reproduction, and Darwin's theory became grounded in the principles of Mendelian genetics, which then ushered in the modern synthesis between evolutionary theory and genetics, forming the basis of modern biology (Dobzhansky, 1962).

Much of psychology also operates this way (for discussions, see Cronbach, 1986, and Rozin, 2001). Theories are proposed and revised in the first-stage process of predicting and discovering interesting phenomena, but the precise mechanisms underlying theoretical claims are often poorly understood prior to the second stage of investigation. We agree with Rozin (2001) that Stage 1 research is a key element of scientific progress in any growing science, and that unnecessary constraints on this type of research can damage the prospects of a discipline to develop into a mature science. As more and more interesting phenomena are discovered, Stage 2 research is initiated; scientists begin to offer competing explanations for them, presumed mechanisms eventually become the subject of debates, and competing accounts for mechanisms are advanced, animating scientific discovery for long periods of time. These debates, in turn, may lead to additional discoveries of interesting phenomena. Only with time and patience are controversies resolved successfully; paradigms sometimes shift, and scientific consensus regarding mechanisms emerges.

Research in cultural psychology can also be broken down into these two stages (see Atran, Medin, \& Ross, 2005, for a similar observation). Stage 1 research typically proposes theories that predict cultural differences in particular psychological processes, whereas Stage 2 research typically seeks to more precisely explain the observed cultural differences by identifying the critical variables that account for them. In the following sections, we articulate how this distinction is useful for understanding how cultural psychology can contribute to psychological science in general.

\section{STAGE 1 CULTURAL PSYCHOLOGICAL RESEARCH: IDENTIFYING CULTURAL DIFFERENCES}

The most straightforward goal of Stage 1 cultural psychological research has been to investigate the extent to which people from different cultures vary in psychological processes. Thus far, the majority of cultural psychological research has been conducted at this stage. Such research is of critical importance to scientific progress in the field, as we explain next.

\section{Stage 1 Research and External Validity}

Psychology has long been criticized for ignoring issues of generalizability of findings, the most prominent criticism being that its restricted database may limit the external validity of its findings (e.g., Gergen, 1973; Medin \& Atran, 2004; Rozin, 2001; Sears, 1986). Social psychology has been especially vulnerable to such criticisms; it investigates questions regarding how people perceive, understand, and respond to the (culturally variable) social world, yet most social psychological research has been conducted within the social environment of middleclass college students. However, nowhere are the limits of the restricted psychological database more problematic than when it comes to cultural representation. A recent review found that 92\% of studies published in the Journal of Personality and Social Psychology, the most influential international journal in these fields, were conducted in North America, and a full $99 \%$ of the studies were conducted in the West (Quinones-Vidal, LopezGarcia, Penaranda-Ortega, \& Tortosa-Gil, 2004). This problem would not be severe if the publications in such journals did not make the implicit or explicit claim that their findings are applicable broadly to humanity at large, rather than to the Western subpopulations from which participants are selected. That a similar inattention to cultural variability has been found in other areas of psychology as well (Norenzayan \& Heine, 2005) underscores how much of the psychological database renders researchers ill prepared to speak confidently of the extent to which many psychological processes are universal.

In many research programs, there are trade-offs between maximizing internal validity and maximizing external validity. The tendency for researchers from a number of psychological disciplines to primarily conduct studies with convenience samples of Western college students, who are disproportionately of European descent and of middle-class background, suggests that psychologists are often inclined to privilege the maintenance of internal validity. That is, studies conducted with convenience samples afford opportunities for researchers to more easily conduct rigorous and systematic series of studies that can address competing hypotheses and rule out methodological artifacts. Although a heavy reliance on convenience samples facilitates the construction of sound theories that are capable of making reliable predictions, the incumbent sacrifice of external validity becomes untenable when researchers raise questions regarding human nature. The limited psychological database raises a cloud of doubt regarding the generalizability of many findings. How can researchers know whether they are studying a phenomenon that is characteristic of humans everywhere or whether they have identified a cultural product that emerges from participating in Western middle-class culture? This 
distinction cannot confidently be made until appropriate crosscultural research tactics are used to test whether the phenomenon meets the criteria of various levels of universality (for a review, see Norenzayan \& Heine, 2005).

The question of the generalizability of research findings is a challenge for science more generally, and perhaps ensuring culturally representative sampling is an onerous technicality that is unnecessary for psychology. For example, it would hardly seem reasonable to say that a reliably observed phenomenon such as social facilitation or transfer-appropriate processing might not be a universal feature of humankind because no one has ever investigated it among, say, the Trobriand Islanders. Such a claim would be dubious because there is no theoretical basis for anticipating any differences in social facilitation or transfer-appropriate processing in this population. Were it the case, however, that one did have compelling a priori theoretical reasons to anticipate that either of these processes would be different among the Trobriand Islanders, psychologists' understanding of that process would potentially be in need of revision if it were indeed found that this population performed reliably differently on relevant tasks.

\section{Stage 1 Research Identifies Cultural Variation in Psychological Processes}

Recent theoretical and empirical developments in cultural psychology have brought the field to the point where researchers need to be mindful of the generalizability of North American, or more generally Western, findings to other cultural contexts. There are a number of rich theoretical models that allow for predictions about the extent to which various models will replicate in other cultural contexts (e.g., D. Cohen \& HoshinoBrowne, 2005; Heine, 2001; Kim, 2002; Markus \& Kitayama, 1991; Medin \& Atran, 2004; Nisbett \& Cohen, 1996; Nisbett, Peng, Choi, \& Norenzayan, 2001; Shweder, Much, Mahapatra, \& Park, 1997; Triandis, 1989). Furthermore, in the past 20 years, since the field of cultural psychology reemerged as a significant discipline, the great extent of documented cultural variation in psychological processes has been rather unexpected, even for cultural psychologists. For example, pronounced and theoretically meaningful cultural differences have been found in fundamental psychological processes, such as eye movements for scanning inanimate scenes (e.g., Chua, Boland, \& Nisbett, 2005); attention (Miyamoto, Nisbett, \& Masuda, 2006); perception of color, space, and time (e.g., Boroditsky, 2001; Levinson, 1997; Roberson, Davies, \& Davidoff, 2000); numerical reasoning (e.g., Gordon, 2004); unspoken thinking (e.g., Kim, 2002); preferences for high subjective well-being (SWB; e.g., Diener, Diener, \& Diener, 1995); the manifestation of psychological disorders such as depression (e.g., Kleinman, 1982; Ryder et al., 2005) and bulimia nervosa (e.g., Keel \& Klump, 2003); the need for high self-esteem (e.g., Heine, Lehman, Markus, \& Kitayama, 1999); and preferences for formal rea- soning (e.g., Norenzayan, Smith, Kim, \& Nisbett, 2002). Research programs in these areas have demonstrated that culture is implicated at a much more fundamental level of psychological processing than what was previously considered, and these findings are forcing researchers to conceive of these phenomena differently than they had before.

Predicted cultural differences have also emerged in a diverse array of phenomena, including how people handle contradiction (e.g., Peng \& Nisbett, 1999), prevention and promotion orientations (e.g., Lee, Aaker, \& Gardner, 2000), self-concepts (e.g., Cousins, 1989), moral intuitions and reasoning (A.B. Cohen \& Rozin, 2001; Miller \& Bersoff, 1992), tendencies to make situational and dispositional attributions (e.g., Choi, Nisbett, \& Norenzayan, 1999; Morris \& Peng, 1994), preferences for choices made by oneself or by others (e.g., Iyengar \& Lepper, 1999), the nature of friendships and enemyships (e.g., Adams, 2005), cognitive dissonance (e.g., Heine \& Lehman, 1997b; Kitayama, Snibbe, Markus, \& Suzuki, 2004), memories for focal and background objects (e.g., Masuda \& Nisbett, 2001), motivations for uniqueness (e.g., Kim \& Markus, 1999), certain kinds of category-based inductive reasoning (e.g., Medin, Ross, Atran, Burnett, \& Block, 2002), daily variability in affective experiences (Oishi, Diener, Napa Scollon, \& Biswas-Diener, 2004), the importance of romantic love in marriage decisions (R. Levine, Sato, Hashimoto, \& Verma, 1995), the pace of life and time perspective (R.V. Levine \& Norenzayan, 1999), preferred decisions in the ultimatum game (e.g., Henrich et al., 2005), feelings of control (e.g., Morling, Kitayama, \& Miyamoto, 2002), and predilection for violence in response to insults (e.g., Nisbett \& Cohen, 1996), to name several. Systematic cultural differences have also been found in early childhood (e.g., Grossmann, Grossmann, Spangler, Suess, \& Unzner, 1985; Imai \& Gentner, 1997; Tardif, 1996), underscoring just how embedded psychological life is within cultural experiences.

Furthermore, many of these cultural differences are pronounced in magnitude. Meta-analyses reveal large effects (average $d>.80$ ) for the difference in the magnitude of selfenhancement motivation between East Asians and Westerners (Heine \& Hamamura, 2006), moderate to large effects for cognitive differences between East Asians and Westerners (average $d=.60$; Miyamoto, Kitayama, \& Talhelm, 2006), and smaller effects for cultural differences in self-report measures of individualism and collectivisms between Asians and Americans (average $d \mathrm{~s}=.39$ for individualism and .24 for collectivism; Matsumoto, 2006; Oyserman, Coon, \& Kemmelmeier, 2002). In general, the cultural differences tend to be more pronounced in studies that compare behaviors that reflect implicit psychological tendencies and less pronounced in studies that compare explicit self-reported cultural values on subjective Likert scales (for discussion, see Heine, Lehman, Peng, \& Greenholtz, 2002; Kitayama, 2002).

Stage 1 cultural psychological research is an ongoing project as more and more theories are developed and psychological 
phenomena are tested in a growing array of cultures. As it progresses, this enterprise will paint an increasingly detailed picture regarding the kinds of processes that are most affected by cultural influences, and those that operate the most independently of cultural context. It is difficult to know a priori which psychological processes are most susceptible to cultural variation, so there is no alternative to solid, programmatic Stage 1 research. For example, growing research indicates that attentional processes, initially believed to be fixed and universal, are in some respects highly responsive to cultural experience (e.g., Chua et al., 2005). Conversely, some core aspects of reasoning about other peoples' mental states (or theory of mind), initially believed to be a folk theory that is culturally malleable to a large degree, appear to develop in remarkably similar ways across cultures (e.g., Callaghan et al., 2005).

One important component of Stage 1 research has been to identify the specific situations in which some cultural differences in psychological processes are made manifest. Cultural differences in various processes are often fluid and do not emerge uniformly as main effects; they often are evident only when certain contextual variables are present. For example, people participating in cultures of honor are not more aggressive than other people across all situations; rather, their aggression emerges specifically in situations in which their honor has been slighted (Nisbett \& Cohen, 1996); the Protestant work ethic does not encourage an overall more detached attitude toward relationships, and cultural differences emerge only when Protestants and non-Protestants are engaged in a work task (e.g., Sanchez-Burks, 2002); East Asians do not always prefer intuitive reasoning strategies more than Westerners, but show the same preferences and skills for formal reasoning when completing abstract tasks (e.g., Norenzayan et al., 2002). In sum, much Stage 1 cultural psychological research has targeted the sensitivity of various psychological processes to situational variables and investigated how cultural differences often appear only in specific contexts.

A second key focus of Stage 1 research has been to conduct systematic series of studies to rule out competing artifactual accounts of cultural differences. A particular challenge of conducting psychological research across cultures is that there are many unique methodological concerns that arise regarding the interpretability of findings (for reviews, see D. Cohen, in press; Greenfield, 1997; and van de Vijver \& Leung, 2000). The wide array of methodological artifacts that are of concern to cultural psychologists has resulted in research on cross-cultural comparability developing into an enterprise in and of itself. Efforts to determine the validity of cultural differences constitute a large part of the studies that are conducted in Stage 1 cultural psychological research.

In sum, the range of identified cultural differences in psychological phenomena has expanded significantly in the past 20 years. Many of these findings have emerged in the wake of recent theoretical developments in cultural psychology, most notably the distinction between independent and interdependent construals of self (Markus \& Kitayama, 1991) and individualismcollectivism (Triandis, 1989). These theoretical developments, coupled with the burgeoning database of documented cultural variation in fundamental psychological processes, challenge psychologists to be hesitant in assuming that findings that emerge from a single population must necessarily be psychological universals (Norenzayan \& Heine, 2005).

\section{Stage 1 Cross-Cultural Research Informs Theories About Universals}

Stage 1 cultural psychological research is as important in documenting robust similarities across cultures as it is in documenting variability. Such research allows psychologists to identify the extent to which psychological phenomena are culture-specific or are psychological universals (Norenzayan \& Heine, 2005; Norenzayan, Schaller, \& Heine, in press). We submit that the restricted database that has historically characterized psychological research has led researchers to inherit a sense of "culture-blindness" whereby observed findings in one's own culture are assumed to be universal. Furthermore, because some degree of universality is often a central assumption of evolutionary explanations, this culture-blindness is of particular relevance to evolutionary explanations, and greatly complicates efforts to articulate how particular psychological phenomena may have evolved.

For example, consider the question of whether a need for positive self-regard is a psychological universal. One way to approach this question is to conceive of positive self-regard as self-enhancement, which is usually operationalized as tendencies to dwell on and elaborate positive information about the self relative to negative information (Heine, 2005b). With this operationalization, it is clear that people from Western cultures are motivated to have positive self-regard, as across dozens of different methods, Westerners show consistent and pronounced self-enhancement (average $d=.86$ ). In contrast, the same methods have revealed an average $d$ of -.02 for East Asians (Heine \& Hamamura, 2006). Thus, a need for positive selfregard operationalized as self-enhancement appears to be far weaker, if not largely absent, among people participating in East Asian cultural contexts (see Heine, Kitayama, \& Hamamura, in press, and Sedikides, Gaertner, \& Vevea, 2005, for some disagreement about the evidence regarding this conclusion).

Given these findings, how might one consider the evolutionary origins of motivations for positive self-regard? On the basis of the consistent evidence for self-enhancement among Westerners, a variety of evolutionary accounts have been offered for the emergence of this motivation. For example, the self-enhancement motive has been posited to have been selected (a) as a gauge of changes in one's status within dominance hierarchies (Barkow, 1989), (b) as a barometer of the vulnerability of one's social relationships (Leary, Tambor, Terdal, \& Downs, 1995), 
or (c) to stave off the debilitating effects of existential anxieties arising from the awareness of one's impending death (Pyszczynski, Greenberg, \& Solomon, 2004). However, these theories are rendered less compelling when one considers the relative lack of self-enhancement motivations that is evident among East Asians, especially as it seems that concerns with status, social relationships, and death are at least as strong in East Asia as they are in the West (e.g., Heine, 2001; Heine, Harihara, \& Niiya, 2002).

We suggest that compelling evolutionary accounts for the origins of psychological processes need to consider the adaptive value of the processes at a level of abstraction where universality is more evident, or they need to specify the conditions under which those processes are operating (Norenzayan \& Heine, 2005). For example, positive self-regard can also be considered in terms of strivings to be the kind of person viewed as appropriate, good, and significant in one's culture (e.g., Crocker \& Park, 2004; Heine et al., 1999). At this level of analysis, a need for positive self-regard is a plausible candidate for a psychological universal, and we propose that the most compelling evolutionary accounts for this motivation will be targeted at this level (see Heine, Proulx, \& Vohs, 2006). In sum, cultural variation identified by Stage 1 research programs serves to highlight the level of analysis at which evolutionary accounts might most successfully be proposed.

Future Challenges and Opportunities in Stage 1 Research Over the past 20 years, Stage 1 cross-cultural research has enjoyed a period of tremendous growth. What might happen over the next 20 years? With the humility to recognize that predicting the future is best left to fortune-tellers and investment bankers, we venture to suggest some directions that we think would prove to be fruitful.

One striking shortcoming of Stage 1 cultural psychological research thus far is that the majority of the most influential research has been focused on comparisons of North Americans and East Asians. Perhaps it is understandable that North Americans specifically and Westerners more generally have usually served as the point of comparison in these studies, given that the majority of psychological theories have emerged from these samples. However, the focus on comparisons between these two cultural groups has resulted in a pronounced neglect of other cultures. We suggest that East Asians have been the primary target of comparison because recent cultural psychological research has built upon the ideas of Markus and Kitayama (1991), who proposed a model that was largely based on a contrast of Western and East Asian cultures. The richness of that model has allowed for a growing number of theoretical advances to be built upon this initial foundation, leading to a wide variety of predictions for specific differences in the ways that East Asians and North Americans are likely to differ in their psychology (e.g., D. Cohen \& Gunz, 2002; Heine et al., 1999;
Nisbett et al., 2001; Norenzayan et al., 2002; Oishi et al., 2004; Suh, 2002). Furthermore, in many ways, cross-cultural comparisons between East Asians and North Americans have made for strong arguments for specific cultural differences, as the samples that are typically contrasted (university students in the two cultural regions) are similar in so many other respects (i.e., they tend to be from highly industrialized, middle-class, urban environments, and the participants tend to be highly educated and cosmopolitan) that there are fewer possible demographic and cultural variables that could potentially account for the differences than there are with many other kinds of cross-cultural comparisons. The emergence of reliable and pronounced differences between groups that share so many important societal and ecological features suggests that there should be at least as broad and expansive differences in other regions of the world that are less industrialized.

We call for cultural psychological research to grow beyond comparisons of East Asians and Westerners. At present, despite the growth of cross-cultural research, psychologists still know embarrassingly little about the psychological processes of the majority of cultures of the world. There appear to be many opportunities to identify important cultural differences for researchers enterprising enough to launch psychological expeditions into relatively unexplored terrain. In particular, we think the role of culture in psychological functioning should become especially evident when small-scale societies are studied. Although such research is methodologically challenging, it stands to greatly advance understanding of the ways that culture is implicated in psychology, given the multitude of theoretically important differences in cultural experience. There has already been much excellent and influential work conducted with such groups (e.g., Atran et al., 2005; Bailenson, Shum, Atran, Medin, \& Coley, 2002; Cole, Gay, \& Glick, 1968; Gordon, 2004; Henrich et al., 2005; Levinson, 1997; Medin \& Atran, 2004; Segall, Campbell, \& Herskovits, 1963), much of it having been done to make arguments for psychological universals (e.g., Barrett \& Behne, 2005; Ekman, Sorenson, \& Friesen, 1969; Levenson, Ekman, Heider, \& Friesen, 1992). We hope that more researchers pursue the important questions that can be answered only by exploring such samples. Other fruitful but underexplored avenues of cross-cultural research include religious differences in the world today (e.g., A.B. Cohen \& Rozin, 2001; Hansen \& Norenzayan, in press; Sanchez-Burks, 2002; Shweder et al., 1997) and the extent to which findings from middle-class samples generalize to working-class ones (e.g., Snibbe \& Markus, 2005). Given psychology's reliance on industrialized, highly secular, and middle-class samples, broadening Stage 1 research in these ways is critical for determining the generalizability of findings.

A second shortcoming of past Stage 1 cultural psychological research is that it has largely been limited to explorations of the extent to which theories and phenomena that have been developed and identified in the West generalize to non-Western 
cultures. An initial impetus of Stage 1 research has been to test the generalizability of assumed universals originally documented in the West. However, it is likely that there are psychological processes that are common in other cultures but would not generalize well to the West, and the study of such processes would be equally informative in addressing questions regarding human nature. Such kinds of "indigenous" phenomena (meaning that they are indigenous to cultures outside of North America) have thus far been most saliently identified in work on psychopathology. For example, a number of psychological disorders, such as koro and latah in Southeast Asia (Ngui, 1969; Suwanlert, 1988), taijinkyofusho and hikikomori in Japan (Cousins, 1990; Sakai, Ishikawa, Takizawa, Sato, \& Sakano, 2004), dhat syndrome in South Asia (Obeyesekere, 1985), susto in Latin America (Rubel, O'Nell, \& Collado, 1985), and malgri among some Australian aboriginal groups (Cawte, 1976), are strikingly different from any conditions that have been identified in North America (see Kleinman, 1988; Tseng, 2001). Cross-cultural research on emotions has also identified a number of emotions that are central to the lives of people from other cultures, yet do not readily fit into any of the taxonomic schemes within the West (e.g., liget in Ilongot-Rosaldo, 1980; amae in Japan-Doi, 1971; iklas in Java-Geertz, 1959). Furthermore, even if a given phenomenon is recognizable in Western culture, it may be overlooked because it is not of central importance in Western samples. However the same phenomenon could be of great importance in many other cultures.

We suggest that a shift from exploring whether Westernidentified phenomena generalize elsewhere to exploring whether other indigenously identified phenomena generalize to the West would open up many fascinating and important avenues to explore, and would greatly advance understanding of cultural variation and universality of psychological processes. To cite an example, the notion of "face" is far more elaborated and takes on different meanings within East Asia than in the West, and this leads to specific psychological predictions that can be tested (e.g., Chang \& Holt, 1994; Heine, 2005a). Likewise, a type of dialectical thinking that emphasizes constant change and, unlike the Hegelian dialectic, is tolerant of apparent contradiction likely would not have been investigated among Westerners if it had not first been identified among Chinese (e.g., Peng \& Nisbett, 1999). We think psychological research would benefit in important ways if greater attention were directed toward the study of phenomena that are less familiar in the West.

We also suggest a third direction that we hope Stage 1 cultural psychological research will follow more in the coming years. One of the strongest arguments for the role of culture in shaping psychological processes is expressed in the Whorfian hypothesis (Whorf, 1956). Simply put, this is the hypothesis that language influences thought (the more extreme version of this hypothesis, the notion that language determines thought, has largely been demonstrated to be untenable). To the extent that this hypothesis of linguistic relativity is correct, one way that cultures shape psychological functioning is through the languages that are spoken. Although the Whorfian hypothesis benefits from a certain intuitive appeal (e.g., consider the rationale behind politically correct speech), for the most part it was dismissed by linguists and psycholinguists in the latter half of the 20th century. One key reason for this dismissal can be traced to work on color perception by Berlin and Kay (1969) and Rosch Heider (1972), who found evidence of universal color perception across cultures with languages having highly divergent color terms. The evidence against linguistic relativity from these research programs was widely interpreted to generalize to any arguments made in support of the Whorfian hypothesis. Recent research, however, has called into question the findings from the key studies of Rosch Heider (Roberson, et al., 2000; also see Lucy \& Shweder, 1979), and new findings have demonstrated that color perception is significantly affected by a language's terms for color (Roberson, Davidoff, Davies, \& Shapiro, 2005; Roberson et al., 2000). Furthermore, other research has demonstrated how linguistic differences can dramatically affect people's perceptions of and reasoning about space (e.g., Levinson, 1997), time (Boroditsky, 2001), and numerical quantities (Gordon, 2004; Pica, Lerner, Izard, \& Dehaene, 2004). We anticipate that this recent renewal of interest in linguistic relativity will pave the way for a number of other important cross-linguistic and crosscultural hypotheses to be tested, thereby opening up expansive new avenues for cultural psychological research.

\section{STAGE 2 CULTURAL PSYCHOLOGY: EXPLAINING CULTURAL DIFFERENCES}

Stage 1 cultural psychological research serves an important function in expanding the database of psychology and painting a more accurate picture of the contours of human nature. Arguably, however, it is Stage 2 research that makes the most significant contribution to the science of psychology. Stage 2 cultural psychological research seeks to explain how cultural differences in psychological processes are produced and sustained. Stage 2 research firmly hinges on Stage 1 research, as genuine cultural differences in psychological processes serve the important function of spotlighting potential psychological mechanisms. We agree with Matsumoto and Yoo (2006, this issue) that crosscultural research exploring underlying mechanisms is critical in psychology because it is the best way-perhaps the only way- to disentangle the effects of multiple variables that tend to co-occur in a given culture but not across cultures. For example, Stage 2 cross-cultural research is needed to assess the relative effects of age-related growth versus schooling on cognitive development. Age and schooling are confounded in Western cultures, but not, for example, in small-scale cultures. By comparing children's cognitive development in a Western culture with children's cognitive development in a culture where children may or may not experience formal schooling, one can disentangle the relative contributions of these two variables (e.g., Stevenson, 1982). 
A simple analogy of how cultural differences serve the function of identifying psychological mechanisms can be seen in the study of neuroscience. One endeavor that clarifies the functioning of normal brains to neuroscientists is examination of the functioning of brains that have been selectively impaired. For example, neuroscientists were able to greatly increase their understanding of how people forecast future events when Phineas Gage lost this ability, along with much of his medial prefrontal cortex. The difference between Gage's brain and the brains of other individuals, and the difference between his forecasting ability and that of others, spotlighted an obvious place to search for the neural foundation of forecasting skills. In this way, Gage's more unfamiliar mind deepened understanding of the intact minds that neuroscientists more frequently encounter.

Likewise, observed cultural differences in psychological processes (although of course not indicating damage or abnormalities!) provide an opportunity for gaining new understanding of those processes. When one finds that a certain psychological process identified in one culture is absent in another, or weaker or more pronounced, one knows that a key mechanism underlying that process is something that is differentially distributed between those populations. For example, the fact that people from Western cultures self-enhance in ways that East Asians do not (e.g., Heine \& Lehman, 1997a) indicates that self-enhancement hinges importantly on a mechanism that is more prevalent in Western than East Asian cultures. Basing their reasoning on Markus and Kitayama's (1991) arguments that Western cultures are better characterized by independent construals of self than are East Asian cultures, Heine et al. (1999) hypothesized, and empirically demonstrated, that selfenhancement is critically tied to independent self-construals. The previously identified cultural difference in self-construals served as a useful starting point for making sense of the cultural differences in self-enhancement. Cultural differences thus serve to spotlight where the most productive efforts can be directed in searching for underlying mechanisms. Hence, findings from research with East Asian participants do not just deepen understanding of minds in East Asian cultures; they also deepen understanding of minds in general. In this way, cross-cultural research findings are relevant and important even for researchers who are not interested in the question of cultural influence per se. Stage 2 cultural psychological research provides an additional tool researchers can use to clarify what mechanisms are behind particular psychological processes. However, questions in Stage 2 are quite different from those of Stage 1. Appropriate research tools are needed in this second stage of research.

\section{Methodological Strategies for Stage 2 Cultural}

\section{Psychological Research}

There are a few strategies by which underlying mechanisms of cultural differences can be explored in Stage 2 research. We describe them here.

\section{Mediational Studies Involving Trait Measures}

One Stage 2 strategy is to examine whether trait measures of relevant theoretical constructs mediate cultural differences. First, cultural differences are identified in one measure (e.g., embarrassability; Singelis, Bond, Lai, \& Sharkey, 1999). Second, cultural differences are identified in a second measure (e.g., interdependent self-construals). Third, the data are analyzed to determine whether the two constructs (i.e., embarrassability and interdependence) are related in the predicted direction. If so, the fourth step is to examine whether the cultural differences in one construct (e.g., interdependence) mediate the cultural differences in the other construct (e.g., embarrassability). Variants on this strategy have been employed in a number of different research endeavors (e.g., the relations between individualism and high SWB, in Diener \& Diener, 1995; between independence and self-enhancement, in Heine \& Renshaw, 2002; between holistic thinking and judgments of causal relevance, in Choi, Dalal, Kim-Prieto, \& Park, 2003; and between self-esteem and the similarity-attraction effect, in Heine, Foster, \& Spina, 2005).

However, such efforts to identify mediators through the correlational strategies described (for more thorough procedural descriptions, see Baron \& Kenny, 1986) are not always particularly effective. Spencer, Zanna, and Fong (2005) persuasively argued that in many situations, experimental strategies to detect underlying psychological processes are preferred to correlational strategies. Specifically, in situations in which it is difficult to confidently measure the theorized process, experimental strategies can provide a more effective means to identify the mediating variable. Because measurement of cultural constructs is compromised by a variety of methodological artifacts specific to cross-cultural comparisons (e.g., D. Cohen, in press; Heine, Lehman, et al., 2002), and often these measures do not show good evidence of measurement equivalence across cultures (van de Vijver \& Poortinga, 2002), correlational attempts at mediation are likely to be less successful in many cross-cultural studies. We agree with Matsumoto and Yoo (2006, this issue) that measures of cultural constructs such as independent-interdependent construals of self are especially methodologically suspect (T.R. Levine et al., 2003), and we suggest that this diminishes their utility in mediational designs.

Furthermore, we emphasize that trait measures capture people's self-reflective awareness of their own thoughts and behaviors; however, much of people's mental processes lies distinctly outside of consciousness (e.g., Bargh, Gollwitzer, Lee-Chai, Barndollar, \& Trotschel, 2001; Nisbett \& Wilson, 1977). Verbal reports can be problematic because participants may not have direct introspective access to their own beliefs, values, or mental processes in general (Nisbett \& Wilson, 1977), or they may (often unconsciously) distort or misrepresent their responses for cognitive and motivational reasons (see, e.g., Schwarz, 1999). This is problematic for the study of culture, because the cultural variables that are purported to influence psychological processing 
(e.g., customs, scripts, lay theories) are typically tacit and outside of individuals' awareness. In the words of Kitayama (2002), echoing this point of the inherent opaqueness of cultural variables, "What culture is to humans is what water is to fish" (p. 90). For example, Americans tend to prefer unique shapes (Kim \& Markus, 1999), and East Asians tend to rely more on familyresemblance cognitive strategies than Americans do (Norenzayan et al., 2002), but these tendencies are largely invisible to Americans and East Asians, respectively, and become apparent to them only through direct cultural contrasts. It is unlikely that self-report measures of people's preferences for unique shapes or reliance on family-resemblance cognitive strategies would reveal cultural differences as reliably, or to the same magnitude, as measures obtained through experimental contrasts. Therefore, efforts to measure cultural variables using trait measures will often be compromised by people's inability to accurately report on their cultural beliefs and practices. Next, we describe some experimental strategies that can avoid the problems inherent in trait measures (granted, experimental methods have their own unique set of weaknesses) in attempts to identify mechanisms underlying cross-cultural differences.

\section{Priming Cultural Constructs}

One strategy frequently used to explore mechanisms is to prime constructs hypothesized to vary across cultures and examine whether such priming can lead people from one culture to respond more like those of another culture. For example, growing experimental evidence indicates that temporarily inducing independent or interdependent self-orientation affects analytic and holistic processing in predictable ways (Kühnen, Hannover, \& Schubert, 2001: Kühnen \& Oyserman, 2002). In one series of studies, Kühnen and his colleagues first primed German participants with either independence ("think of how different you are from family and friends") or interdependence ("think of how similar you are to family and friends"). Subsequently, participants' responses on an unrelated perceptual task were measured. Results indicated that activation of independent selfconstruals led to more field independence and activation of interdependent self-construals led to more field dependence, demonstrating that independence and interdependence have a causal effect on the kinds of perceptual differences that have been identified in other cross-cultural research (e.g., Ji, Peng, \& Nisbett, 2000). Many other studies have also utilized this priming method for articulating the mechanisms underlying cultural differences, showing, for example, the effects of interdependence on enemyship experience (Adams, 2005), on tolerance for financial risks (Mandel, 2003), on prevention motivations (Lee et al., 2000), and on collectivist social values (Gardner, Gabriel, \& Lee, 1999). Other priming studies have demonstrated the effects of complex visual scenes on attention to the field (Miyamoto, Nisbett, \& Masuda, 2006), of dialectical orientations on self-esteem (Spencer-Rodgers, Peng, Wang, \&
Hou, 2004), and of distinctiveness on independent self-descriptions (Trafimow, Triandis, \& Goto, 1991).

\section{Other Experimental Methods}

A variety of other experimental or quasi-experimental approaches have also been used to identify mechanisms underlying cultural differences. One approach is to identify key experiences that vary across cultures and measure whether greater exposure to these experiences leads to changes in psychological variables. For example, Koo and Choi (2005) hypothesized that training in Oriental medicine fosters a holistic way of thinking. They found that Korean students in Oriental medicine more strongly believed in a cyclic pattern of change and considered a broader range of explanatory factors (both hallmarks of holistic reasoning) than did comparable students who were not being trained in Oriental medicine. The data showed a chronological trend, with holistic tendencies becoming stronger the longer students were exposed to training in Oriental medicine, and this trend remained after age differences were accounted for. Similarly, Kitayama, Markus, Matsumoto, and Norasakkunkit (1997) reasoned that self-enhancing and self-improving tendencies emerge from participating in specific cultural situations that encourage such tendencies. They developed a situation-sampling technique to demonstrate that Americans became more self-improving when they imagined themselves in Japanese situations, and, likewise, that Japanese became more self-enhancing when they imagined themselves in American situations. Such a method can also be used to identify the specific features of situations or social experiences that are associated with particular psychological processes (e.g., Morling et al., 2002).

Using a different approach, Heine et al. (2001) tested the hypothesis that cultural differences in self-improving motivations are related to theories of abilities. They presented people with a task that contained instructions suggesting either that it measured abilities that were incremental or that it measured abilities that were entity based. The results indicated that incremental-abilities instructions led Americans to respond more like Japanese, whereas entity-abilities instructions led Japanese to respond more like Americans. By noting the kinds of information in the instructions that people responded to, Heine et al. were able to identify the default strategies that people in different cultures pursued.

Employing another technique, Heine, Takemoto, and Moskalenko (2005) investigated whether self-critical motivations are related to objective states of awareness. They manipulated an objective state of awareness by placing people in front of a mirror and found that the mirror led Americans to show more self-critical motivations, like the Japanese, whereas Japanese remained largely unaffected by the mirror (suggesting that they were more chronically in a state of objective self-awareness; also see D. Cohen \& Hoshino-Browne, 2005). 
The experimental strategies in the studies just mentioned are similar in that they all involve manipulating or measuring the accessibility of ideas or experiences that are hypothesized to be more chronically accessible in one culture than in another. Another Stage 2 strategy is to decouple the presumed underlying cultural process (e.g., independence-interdependence) from the conventional populations of comparison (e.g., East Asian vs. Western). For example, if the differences between East Asians and Westerners in analytic versus holistic thinking are explainable in terms of degrees of independence-interdependence, then other cultures that differ in independence and interdependence should show parallel differences in analytic versus holistic processing. Kühnen, Hannover, and Roeder (2001) tested this hypothesis with participants in two individualistic cultures, the United States and Germany, and two collectivistic ones, Russia and Malaysia, and found results consistent with this hypothesis in the domain of perceptual processing. That is, Russians and Malays showed higher levels of holistic thinking than the other cultural groups, whereas Americans and Germans showed higher levels of analytic thinking than the Russians and Malays (also see Knight, Varnum, \& Nisbett, 2005, for parallel differences between Western and Eastern Europeans and between Northern and Southern Italians). New research has gone beyond independence-interdependence to examine additional cultural affordances that may explain cultural differences in cognition. Miyamoto, Nisbett, and Masuda (2006) showed that (a) randomly sampled Japanese scenes are more visually complex than randomly sampled American scenes, judged by objective as well as subjective measures, and (b) both Japanese and American participants exposed to Japanese scenes were more likely to show holistic processing in a subsequent task than were participants exposed to American scenes.

Another useful approach is the triangulation strategy, proposed and discussed in Bailenson et al. (2002) and Medin and Atran (2004). This is a two-step process that is designed to shed light on the source of a cultural difference. In the first step, a psychological phenomenon is examined across two cultures, A and $\mathrm{B}$, that are known to vary on a theoretically relevant dimension and are also predicted to vary in that phenomenon. In the second step, a third culture, C, that varies from B but not A on a second theoretically relevant dimension is included. Thus, cultures A and B differ on the first dimension, whereas cultures $\mathrm{B}$ and $\mathrm{C}$ differ on the second dimension. This strategy sheds light on the specific population variable that is implicated in the psychological difference between A and B. Studies on categorybased induction in folk biological reasoning (Bailenson et al., 2002; see also Medin \& Atran, 2004) have illustrated the usefulness of this strategy in facilitating explanations for cultural differences. For example, Medin and Atran (2004) demonstrated that unlike American college students, Maya villagers in Guatemala and Americans with biological expertise (park maintenance workers, who share aspects of American national culture with American college students but share aspects of biological expertise with the Maya) do not typically use the diversity heuristic in inductive reasoning about plants and animals. The diversity heuristic is a widely replicated inductive reasoning phenomenon that relies on a coverage strategy-the more diverse the premise categories, the stronger is the inductive inference to a conclusion category that subsumes these premise categories. Medin and Atran's studies revealed that immersion in the biological world is a key factor that precludes the diversity heuristic, and instead leads to a preference for ecological reasoning, which, unlike the diversity heuristic, relies on knowledge about the interrelations among plants and animals and their habitats to make causal inferences about biological properties. It appears that in the absence of biological expertise, people, such as Western college students, revert to the diversity heuristic.

In sum, in recent years, building upon the findings from Stage 1 research, as well as extending the earlier theoretical foundations that had been developed (e.g., Markus \& Kitayama, 1991; Nisbett et al., 2001), a variety of different methods have been used to search for mechanisms underlying cultural differences. Although still in its infancy, this Stage 2 research has deepened researchers' understanding of psychological mechanisms in ways that would have been less likely to emerge had researchers never considered samples outside of Western culture.

\section{Explanations for Group Differences}

Theoretically, psychological differences among human groups can be accounted for in three distinct ways (after methodological artifacts have been ruled out): (a) Exposure to different local ecological conditions may cause underlying psychological mechanisms to be expressed differently (evoked culture); (b) people may acquire psychological tendencies through social learning processes that are biased in favor of learning from ingroup members (transmitted or epidemiological culture); or (c) population differences in gene frequencies may be associated with particular behavioral tendencies (noncultural genetic variation). Next, we briefly examine each possibility.

\section{Evoked Culture}

Human groups occupy vastly different ecological niches (Edgerton, 1971) that may evoke different cognitive tendencies to solve the same problems of human existence, resulting in divergent psychological tendencies (D. Cohen, 2001). There are two variants to this claim. Evoked culture could emerge because different environments select different psychological processes or because the same psychological process are expressed differently in different environments. Tooby and Cosmides (1992; see also Fessler, in press, for discussions) proposed that behavioral variation may emerge when different local environmental triggers act on the same underlying psychology. To illustrate how evoked culture operates, Tooby and Cosmides discussed how the 
same food-sharing mechanism can lead to different cultural norms depending on the degree of variability in foraging or hunting success. Where foraging or hunting success is highly variable across time, egalitarian norms for food sharing and sanctions against hoarding are strong; this is not the case when the supply of food is relatively stable. Similarly, Gangestad, Haselton, and Buss (in press) drew on evoked culture as the explanation for cultural variation in mate preferences. They argued that the same underlying preference for mates exhibiting indicators of health interacts with an ecological cue to produce cultural variation-features signaling health are more valued in potential mates where parasite prevalence is high than where it is low. Evoked culture is also a partial explanation for cognitive differences between East Asians and North Americans, as indicated by recent findings (Miyamoto, Nisbett, \& Masuda, 2006) on the effects of visual environments-Japanese visual scenes evoked holistic cognitive tendencies even among Americans.

\section{Transmitted or Epidemiological Culture}

We propose that the complex cognitive capacities that enable cultural transmission, such as various forms of social learning, are the primary engine that produces the bulk of stable variation across groups (Henrich \& Boyd, 1998; Richerson \& Boyd, 2005). Transmitted or epidemiological culture is prototypically what most social scientists and cultural psychologists consider culture (Nisbett, 2003; Norenzayan, in press; Richerson \& Boyd, 2005; Sperber 1996). It refers to the fact that genetically similar people living in similar environments may possess strikingly different beliefs, practices, and psychological tendencies that they acquire from others in their group. Culture emerges when information is transmitted socially through social learning mechanisms such as imitation and instruction (Tomasello, Kruger, \& Ratner, 1993); it is also a by-product of communicative processes such as gossip, conversations, and telling of stories (Schaller, 2001). People acquire and transmit substantial amounts of information that subsequently alters their behavior in profound ways. Most cultural differences examined by cultural psychologists are due to transmitted or epidemiological culture, although there have been relatively few direct investigations of how transmission processes give rise to cultural differences.

It is useful to distinguish evoked and transmitted culture as explanations of cultural differences, yet in actuality these two processes reflect a continuum rather than a dichotomy. That is, psychological structures may vary in degree between being entirely innately prepared, at one extreme, and being entirely reliant on socially transmitted mechanisms, at the other. Mechanisms at the former extreme are activated in individuals by the mere presence of an appropriate ecological cue; those at the latter extreme require substantial social transmission (including processes of imitation and instruction) for their activation (Fessler, in press). Many psychological structures fall in between these two extremes. Furthermore, these two processes work in tandem to produce and maintain cultural diversity (Norenzayan, in press). Nisbett and Cohen's (1996) work on the culture of honor illustrates this point. The U.S. South has a tradition of honor, in which toughness and aggressive response to insults are prized, in a way that they are not in the North. The origin of this difference is a story of evoked culture: Where wealth is easily stolen, as in ecologies supporting herding economies, men stand to benefit by maintaining their honor or developing a reputation for toughness. The South was settled by Scotch Irish herders, whereas the North was settled mostly by European farmers; as a result, a tradition of honor is more prevalent in the South than in the North. But cultural differences persist even when the original economic conditions disappear. The culture of honor continues to flourish in industrialized parts of the U.S. South, even though herding is a thing of the past. The best explanation for the persistence of honor cultures is social transmission, and indeed, a variety of evidence supports this view (D. Cohen, Vandello, Puente, \& Rantilla, 1999; Nisbett $\&$ Cohen, 1996). One possibility is that ecological differences evoke initial responses that vary adaptively across different environments, but then these responses are picked up by processes of transmitted culture, amplified, and perpetuated even when the initial conditions are no longer present (see D. Cohen, 2001).

An important question for future Stage 2 cross-cultural research concerns the relative contributions of evoked and transmitted culture to cultural variation. Richerson and Boyd (2005) proposed the ideal "common garden" thought experiment for this purpose: Take two groups of individuals living in different environments and having very different cultures, and switch them around. Suppose some Inuits with a subsistence based on fishing move into the humid rain forests of the Amazon, and some Yanomamo hunter-gatherers move into the frozen arctic regions of Canada. According to the evoked-culture explanation, the arctic Canadian ecology will quickly trigger the Inuit way of life among the Yanomamo foragers, and as a result, they will cease to resemble their Yanomamo compatriots in the Amazon. According to the transmitted-culture explanation, they will remain more like their Yanomamo compatriots, and without the opportunity to adopt rapidly the cultural repertoire of arctic survival accumulated through thousands of years by the Inuit, they will likely suffer greatly from the harsh climate.

Cultural psychologists could take advantage of naturally occurring "experiments" to isolate the effects of transmitted culture, by comparing groups living in similar environments but with different beliefs and practices. The Amish of the U.S. Midwest, for example, live in the same ecological environment as neighboring German-ancestry farmers, but to this day have maintained beliefs and practices that are markedly different. The complementary strategy would be to measure the effects of a novel ecological variable on a group that shares the same culture; for example, one might examine how farmers in a farming community of the U.S. North differ from individuals who have 
migrated from Northern farming communities to a new environment in which they adopt herding. An example of the former kind of study is one by Rice and Steele (2004), who compared the average SWB in European countries with that in U.S. ethnic groups whose ancestry was derived from those countries. Countries differ markedly in their average SWB, and Rice and Steele found that the differences in SWB across the European countries were mirrored by the differences across their corresponding American ethnic groups, although the magnitude was much smaller. Thus, cultural differences were preserved even after generations of living in the same country, under similar ecological conditions of American middle-class life. Given that group differences in SWB in these samples were likely not genetic, this finding supports the idea that an important psychological variable such as SWB is transmitted socially across generations and can persist for a long time even in a very different environment. Psychologists interested in cultural variation have been slow in adopting such research strategies that are ultimately important in isolating the mechanisms of cultural variation.

\section{Genetic Variation}

A controversial explanation for psychological differences between cultures is that they could derive from genetic differences. This possibility should be examined with care, given the unfortunate history of racism and conquest that has often accompanied biological explanations of group differences (for discussions, see Diamond, 1997, and Gould, 1981). Research in behavioral genetics reveals that within any human population, many psychological traits and tendencies are moderately to substantially heritable (e.g., Plomin, Owen, \& McGuffin, 1994; Roy, Neale, \& Kendler, 1995; Turkheimer, 2000). However, it is crucial to underscore that heritable differences within populations do not indicate heritable differences between populations (for discussion, see Richerson \& Boyd, 2005, and Scarr, 1981). Human groups are overwhelmingly genetically similar to one another, and it is likely that although many behaviors are to some extent heritable within groups, most between-groups differences are overwhelmingly attributable to socially transmitted mechanisms. Nevertheless, a growing body of research continues to identify genes that vary systematically across populations. These include genes associated with distinct blood groups (Landsteiner, 1901), skin color (Jablonski \& Chaplin, 2000), lactose intolerance (Beja-Pereira et al., 2003), and resistance to malaria (Allison, 1954). It is conceivable, then, that some differences that are identified between two cultural groups derive from differential frequencies of specific genes between the two populations.

To the extent that group-level psychological differences are associated with group-level genetic differences, selection pressures must have diverged in different populations. CavalliSforza and Cavalli-Sforza (1995) argued that one should see the greatest differential selection pressures on traits that have had powerful consequences for fitness and that have occurred consistently over long periods of time, such as those related to thermal regulation, pathogen resistance, and diet. Most psychological traits and tendencies are unlikely to meet these criteria, unless genes associated with these traits and tendencies also have yet-to-be-identified psychological side effects, or spandrels. Most large-scale societal changes that separate cultures today-with the possible exception of the agricultural revolution that occurred in some societies 10,000 years agohave very short time frames that minimize the impact of differential selective pressures on the gene pool in different groups. Cultural practices are fluid, and often change quite dramatically over generations, making it unlikely that many specific cultural practices have persisted long enough to have significantly influenced the genome.

Perhaps the best way to empirically address the question of whether variation in genes or in cultural practices underlies group differences in psychological processes is to contrast groups in which race is held constant but cultural context is varied. Immigrants and their descendants provide practical samples that afford this kind of investigation. Empirical results typically show that immigrants and their descendants exhibit psychological processes intermediate to those of members of their heritage culture and their compatriots in their host culture-evidence consistent with a cultural, rather than genetic, explanation for group differences. For example, Asian Americans exhibit psychological tendencies intermediate to those of Asians in Asia and Americans of European descent (e.g., Kitayama et al., 1997; Norenzayan et al., 2002); if anything, Asian Americans more closely resemble European Americans than they do Asians in Asia (Heine \& Hamamura, 2006; Lydens, 1988; Miyamoto, Kitayama, \& Talhelm, 2006). Furthermore, the longer people of Asian descent have been in North America, the more their psychological tendencies resemble those of European Americans, to the point that third-generation Asian Canadians are indistinguishable from Canadians of other cultural backgrounds (Heine \& Lehman, 2004; McCrae, Yik, Trapnell, Bond, \& Paulhus, 1998). At present, we know of no compelling empirical evidence to suggest a genetic basis for the group differences that have been identified in psychological studies. We therefore consider such group differences to be cultural differences, whether their primary origin is evoked or transmitted culture.

\section{Proximal and Distal Explanations of Cultural Differences}

In Stage 2 research, it is also important to distinguish between proximal and distal explanations of cultural differences. Both levels of explanations are important, and they are complementary for understanding how cultural differences originate and persist in populations. Distal explanations are historical analyses that involve social, economic, and geographic factors that may have given rise to culturally stable patterns of thought and behavior. Proximal explanations largely involve 
individual-level psychological processes-including beliefs, knowledge, and experiences with the world-that have been shaped by these historical developments and could be directly implicated in cultural differences in psychology.

Distal explanations of cultural differences are inherently outside the scope of psychological research and require interdisciplinary methods or collaboration with historians, anthropologists, archaeologists, sociologists, and ecologists. These collaborations are not without their challenges, but they can provide fruitful insights into psychological patterns. A fascinating example of a distal account of cultural differences is Diamond's (1997) Guns, Germs, and Steel, in which he traces today's regional differences in wealth, technology, and political institutions to early geographic factors, such as the availability of domesticable plants and animals in a given region and to the shape of coastlines and dominant continental axes.

For a psychological example, consider again Nisbett and Cohen's (1996) work tracing the culture of honor that currently exists in the U.S. South back to the herding-based economies of the first European settlers in that region. Such kinds of distal explanations cannot be tested directly through psychological methods. However, evidence for distal explanations can be derived from investigations of proximal measures regarding how cultural patterns continue to persist even when the original ecological factors that gave rise to them are long gone (D. Cohen, 2001). For example, Cohen and his colleagues have identified a number of proximal mechanisms by which honor cultures are perpetuated. These include the socialization of boys for violence in the event of an insult (D. Cohen, 1998), behavioral rituals for regulating conflict (D. Cohen et al., 1999), men's participation in cultural activities that encourage toughness (D. Cohen, 1998; Nisbett \& Cohen, 1996), the establishment of laws and cultural practices that sustain a culture of honor (D. Cohen, 1996), and pluralistic ignorance regarding the extent to which masculinity is perceived to be linked with honor (D. Cohen, Nisbett, Bowdle, \& Schwarz, 1996). In sum, there is an important distinction between distal and proximal levels of explanation, and Stage 2 research is important for facilitating both levels of explanation.

\section{IMPLICATIONS OF CROSS-CULTURAL RESEARCH FOR SOCIETY AND INTERGROUP RELATIONS}

The study of culture and psychology has important social ramifications that extend beyond the psychological laboratory. Here we consider some broader implications of a psychological science that is attentive to cultural differences.

\section{Cultural Psychology and Stereotyping}

One concern that is sometimes raised regarding cultural psychology is that it smacks of stereotyping, for example, by leading to such conclusions as "Japanese have interdependent selves whereas Americans have independent selves." Is cultural psychology tantamount to stereotyping?
We suggest that, in principle, statements like the example just cited are not different in kind from how one describes other group differences or experimental effects in psychology. That is, they are not essentially different from, for example, statements about the rumination of depressives, the patriotism of people in a mortality-salience condition, the motivated cognitions of people who support a particular position, or, for that matter, aggregatelevel phenomena that do not involve people (e.g., saying that the weather in California is warmer than the weather in Pennsylvania). However, these kinds of descriptions of group differences feel considerably less problematic than saying, "Japanese have interdependent selves." Why might this be? Perhaps perceptions of stereotyping are especially likely to arise when the group that is being referred to is one in which people tend to vest their identity. If people identify with their groups, then statements about those groups would seem to be directly applicable to them, in ways that are different from the ways that statements about other groups apply to them. People obviously identify a great deal with their culture, and as a result may feel pigeonholed when cultural differences are invoked.

Charges of stereotyping tend to be directed more often at cultural psychology than at other fields of psychology. This might be the case because of a belief that statements about cultural differences are essentializing and suggest, for example, that all members of a group have the same psychological characteristic, and that the cultural differences are fixed and immutable, allowing little room for social change. Within-group heterogeneity is an obvious fact of human behavior, and we do not know of any arguments of cultural homogeneity that have been made by psychologists. Perhaps the concern with stereotyping in cross-cultural research is merely linguistic, and therefore can be addressed by making greater efforts to report research findings with more extensive qualifying terminology (e.g., "on average, as a group, people who participate in Japanese cultural contexts are more likely than those who participate in American cultural contexts to display features of interdependent selves, although there is much variation within both cultures"). Whether or not the concern with stereotyping is largely linguistic, efforts to describe cultural differences in ways that take into account the heterogeneity of the samples can sensitize readers to the fact that cultural differences are statistical regularities, not absolute laws.

The concern with stereotyping may also originate from an implicit assumption that identified cultural differences are claimed to be immutable and unchangeable. Of particular concern is whether cultural differences examined by psychologists are perceived as immutable and essentialized because they reflect genetic differences across populations. As discussed earlier, there is no evidence that the group differences in psychology thus far examined by cultural psychologists reflect population-level genetic differences, and there is considerable evidence, derived from much Stage 2 research (e.g., studies showing that people who are primed with ideas more common in 
another culture come to think in ways congruent with the norms from that culture), that they are socially transmitted (for further discussion, see Norenzayan \& Heine, 2005). The perceived immutability of cultures may also derive from an implicit assumption that cultures are proposed to be entities that remain stable across time. As do many other cross-cultural researchers, we view cultures as statistical distributions of beliefs and behaviors across a group of minds, not as unchanging superorganic entities. The burgeoning literature on cultural evolution (e.g., Berger \& Heath, 2005; Norenzayan et al., in press; Richerson \& Boyd, 2005) supports this view, although we also recognize that there are fascinating arguments for the expectation that some cultural elements may persist over time-arguments that are also consistent with a distributional view of culture (e.g., D. Cohen, 2001; Nisbett, 2003). We suggest that misperceptions of the immutable nature of cultural differences help to sustain a concern with stereotyping regarding cultural psychological research, and this concern can be alleviated by the understanding that cultures are best construed as transmitted quasi-stable distributions of shared beliefs, not immutable structures.

Contrasting Culture-Blind and Multicultural Psychologies Considerations of cultural diversity in psychological functioning place cultural psychologists in the crosshairs of another politically charged debate: What is human nature? The two sides of this debate are guided by competing ideologies regarding how to interpret human diversity. One approach is the culture-blind notion that people are the same wherever one goes. Of course, no one believes that any two people are exactly the same. Rather, this belief reflects the view that at some fundamental level, people share some underlying nature or essence (see Shweder, 1990, for an in-depth discussion of this perspective). This consideration of human nature, however well intentioned it may be, carries a significant cost. Maintaining the assumption that people everywhere think the same, when all one really can feel somewhat confident about is how people from one's own culture tend to think, requires the potentially ethnocentric projection of one's own cultural beliefs to understand those from other cultures. This is especially problematic for psychology, as the psychological database is largely based on findings from Westerners, particularly Americans. As a result, the starting point of reference from which the field of psychology considers intercultural relations is often American, or more broadly Western, culture-a practice not without costs. Is the highest level of moral reasoning around the world really one that privileges justice and individual rights above all else (e.g., Kohlberg, 1971; for dissenting views, see Miller \& Bersoff, 1992, and Shweder et al., 1997)? Do people everywhere want more individual choice (Iyengar \& Lepper, 1999; Schwartz, 2004)? Do people everywhere want high self-esteem or high SWB (Diener et al., 1995; Heine et al., 1999)? Is speaking up in class conducive to thinking everywhere (Kim, 2002)? The extent of the documented cultural variation in these and other areas should encourage people to be cautious in inferring shared beliefs and desires across cultures, rather than reflexively assuming that what Americans or Westerners want reflects universally shared desires.

An alternative to the culture-blind approach is the multicultural notion that difference is not tantamount to deficit, and therefore diversity needs to be recognized and appreciated. One potential cost of this view is that it highlights group differences, making cultural membership a salient consideration, and thus making people more vulnerable to stereotyping. However, this approach also allows people to engage with others knowing that those others might not see the world in the same way that they do, and it provides people with a conceptual framework to understand how different life circumstances, assumptions, or experiences may affect thoughts, feelings, and behaviors differently. This is not a hypothetical argument. As reviewed earlier, there are real and significant cultural differences in the ways that people think and feel. Ignoring the reality of these differences would make people susceptible to ethnocentric projections and would only seem to breed ignorance and misunderstandings. We agree with Shweder (2000) that the best strategy for dealing with the thorny question of cultural variation in psychological processes is to be slow at judging other cultures, that is, to be cautious about making value judgments about how someone from a different culture might behave or think. This does not mean that criticizing specific practices of other cultures is unreasonable, but it does mean that criticism is most compelling and constructive when it is sensitive to the dangers of ethnocentric projections and takes into account cultural contexts.

The prejudice-reduction literature in social psychology has emphasized strategies, such as equal-status contact and superordinate goals, that are aimed at breaking down group boundaries and reducing perceptions of group differences. These strategies have been effective to some degree, but they are not without their costs. Their individualist and assimilationist slant leaves little room for cultural diversity, for people to remain different yet tolerant of the cultural other. This is a heavy price to pay in multicultural societies such as North America and Australia, and increasingly Europe. Cultural psychology offers an alternative. Perhaps if people had greater knowledge and appreciation of cultural differences, difference would breed not prejudice, but tolerance. We suggest that the consideration of people from other cultures as having equal status and the consideration of people from other cultures as potentially different are not incompatible, but rather are complementary. Intergroup contact, for example, may lead to greater appreciation of cultural differences as much as it may lead to the dilution of group boundaries. Cultural knowledge could be used in conjunction with individuating information to form culturally sensitive yet nonstereotypical judgments about the other.

In fact, some research indicates that this is indeed possible. Wolsko, Park, Judd, and Wittenbrink (2000) primed White 
Americans with two alternative ideological messages. The colorblind message advocated a race-blind and culture-blind approach to improving interethnic relations ("we are all the same"); the multicultural message took differences as a given and advocated appreciation and respect for cultural differences. Subsequently, participants' attitudes toward Blacks and Hispanics were measured. The results showed that relative to no message, the color-blind and multicultural messages reduced in-group bias and interethnic prejudice about equally. Although the multicultural message increased perceptions of dissimilarity between the in-group and out-group, that perception did not translate into in-group favoritism or out-group hostility. Furthermore, the multicultural message increased stereotyping for both negative and positive traits, but it also increased stereotype accuracy for both types of traits and led to more favorable attitudes toward the out-groups. The results overall suggest that the culture-blind and multicultural strategies, although psychologically quite different, can produce favorable outcomes relative to doing nothing at all. It remains for researchers to explore under what conditions each strategy is more effective in increasing tolerance between cultural groups.

We further suggest that a culture-blind psychology exerts a significant cost on the science of psychology, in that it serves to marginalize psychological research from non-Western cultures. We have had a number of discussions with researchers from nonWestern cultures who have informed us that they tried, and failed, to replicate a well-established Western finding. Some of those people have suggested to us that this "failure" led them to conclude that they were not as talented as researchers as Western psychologists. Indeed, if psychological processes are believed to be universal, and non-Western researchers have difficulty in replicating the findings that come out of the West, then a reasonable conclusion is that those researchers are lacking the acumen to detect these universally available phenomenon. In contrast, with the perspective of a multicultural psychology, the failure of a phenomenon to travel from one culture to another can suggest something meaningful. It can be an opportunity to locate previously unknown boundary conditions for the phenomenon, or to identify an indigenous phenomenon, and make a contribution that has significance to the whole field. The recognition of culture's role in shaping psychological processes should serve to importantly reduce the relative monopoly that Western researchers have had over the field of psychology (see Quinones-Vidal et al., 2004).

We anticipate that political sensitivities will continue to be part of cultural psychological research. Thus far, the majority of cross-cultural psychological research has identified cultural differences that are only mildly controversial, in that they tend to be rather evaluatively neutral and have been observed by comparing cultural groups that are for the most part not engaged in intense political struggles. We recognize that there is no guarantee that future cultural psychological research efforts will continue to focus on relatively uncontroversial topics or to contrast groups that are not involved in emotionally charged political struggles. Indeed, it seems that some of the most important kinds of questions that cultural psychologists could investigate may be precisely those that can clarify how cultural factors are involved in real-world political conflicts or inequities. For example, consider the conflict between many Muslims and some Western journalists and their supporters regarding the publication of caricatures of Muhammad by a Danish and other Western newspapers in 2005 and 2006. Many complex issues are implicated in this conflict. However, an important element is a cultural divide centered on different conceptions of morality in these two cultural groups. For one, moral reasoning is based on a morality of autonomy that favors individual rights and freedoms; for the other, it is based on a morality of divinity that favors purity and sacredness (see Shweder et al., 1997). Greater understanding of cultural diversity in moral-reasoning strategies can raise awareness of the different moral sensitivities that are important in different groups, and might prevent such misunderstandings. Thoughtfully conducted research can illuminate the cultural differences that are implicated in intercultural conflicts and misunderstandings. Reducing intercultural conflict requires transcending differences. We suggest that to transcend differences, one must first understand what it is that divides people.

Acknowledgments-Preparation of this manuscript was supported by grants from the National Institute of Mental Health (R01 MH060155-01A2) and Social Sciences and Humanities Research Council of Canada (410-2004-0795) to Heine and by a grant from SSHRC (410-2004-0197) to Norenzayan. We are especially grateful to Dov Cohen, Shinobu Kitayama, Dick Nisbett, Jeffrey Sanchez-Burks, and members of the Culture and Self lab at the University of British Columbia for their thoughtful comments on an earlier draft of this article.

\section{REFERENCES}

Adams, G. (2005). The cultural grounding of personal relationship: Enemyship in West African worlds. Journal of Personality and Social Psychology, 88, 948-968.

Allison, A.C. (1954). The distribution of the sickle-cell trait in East Africa and elsewhere, and its apparent relationship to the incidence of subtertian malaria. Transactions of the Royal Society of Tropical Medicine and Hygiene, 48, 312-318.

Asch, S.E. (1987). Social psychology. New York: Oxford University Press (Original work published 1952)

Atran, S., Medin, D.L., \& Ross, N.O. (2005). The cultural mind: Environmental decision making and cultural modeling within and across populations. Psychological Review, 112, 744-776.

Bailenson, J.N., Shum, M., Atran, S., Medin, D.L., \& Coley, J. (2002). A birds eye view: Biological categorization and reasoning within and across cultures. Cognition, 84, 1-53.

Bargh, J.A., Gollwitzer, P.M., Lee-Chai, A., Barndollar, K., \& Trotschel, R. (2001). The automated will: Nonconscious activation and 
pursuit of behavioral goals. Journal of Personality and Social Psychology, 81, 1014-1027.

Barkow, J.H. (1989). Darwin, sex, and status: Biosocial approaches to mind and culture. Toronto, Ontario, Canada: University of Toronto Press.

Baron, R.M., \& Kenny, D.A. (1986). The moderator-mediator variable distinction in social psychological research: Conceptual, strategic, and statistical considerations. Journal of Personality and Social Psychology, 51, 1173-1182.

Barrett, H.C., \& Behne, T. (2005). Children's understanding of death as the cessation of agency: A test using sleep versus death. Cognition, 96, 93-108.

Beja-Pereira, A., Luikart, G., England, P.R., Bradley, D.G., Jann, O.C., Bertorelle, G., Chamberlain, A.T., Nunes, T.P., Metodiev, S., Ferrand, N., \& Erhardt, G. (2003). Gene-culture coevolution between cattle milk protein genes and human lactase genes. Nature Genetics, 35, 311-313.

Berger, J., \& Heath, C. (2005). Idea habitats: How the prevalence of environmental cues influences the success of ideas. Cognitive Science, 29, 195-221.

Berlin, B., \& Kay, P. (1969). Basic color terms: Their universality and evolution. Berkeley: University of California Press.

Boroditsky, L. (2001). Does language shape thought? English and Mandarin speakers' conceptions of time. Cognitive Psychology, $43,1-22$.

Boyd, R., \& Silk, J.B. (2003). How humans evolved (3rd ed.). New York: Norton.

Callaghan, T., Rochat, P., Lillard, A., Claux, M.L., Odden, H., Itakura, S., Tapanya, S., \& Singh, S. (2005). Synchrony in the onset of mental-state reasoning: Evidence from five cultures. Psychological Science, 16, 378-384.

Cavalli-Sforza, L.L., \& Cavalli-Sforza, F. (1995). The great human diasporas: The history of diversity and evolution. Reading, MA: Perseus Books.

Cawte, J.E. (1976). Malgri: A culture-bound syndrome. In W.P. Lebra (Ed.), Culture-bound syndromes, ethnopsychiatry, and alternate therapies (pp. 22-31). Honolulu: University Press of Hawaii.

Chang, H.-C., \& Holt, G.R. (1994). A Chinese perspective on face as inter-relational concern. In S. Ting-Toomey (Ed.), The challenge of facework: Cross-cultural and interpersonal issues (pp. 95-132). Albany: State University of New York Press.

Choi, I., Dalal, R., Kim-Prieto, C., \& Park, H. (2003). Culture and judgement of causal relevance. Journal of Personality and Social Psychology, 84, 46-59.

Choi, I., Nisbett, R.E., \& Norenzayan, A. (1999). Causal attribution across cultures: Variation and universality. Psychological Bulletin, $125,47-63$.

Chua, H.F., Boland, J.E., \& Nisbett, R.E. (2005). Cultural variation in eye movements during scene perception. Proceedings of the $\mathrm{Na}$ tional Academy of Sciences, USA, 102, 12629-12633.

Cohen, A.B., \& Rozin, P. (2001). Religion and the morality of mentality. Journal of Personality and Social Psychology, 81, 697-710.

Cohen, D. (1996). Law, social policy, and violence: The impact of regional cultures. Journal of Personality and Social Psychology, 70, 961-978.

Cohen, D. (1998). Culture, social organization, and patterns of violence. Journal of Personality and Social Psychology, 75, 408-419.

Cohen, D. (2001). Cultural variation: Considerations and implications. Psychological Bulletin, 127, 451-471.

Cohen, D. (in press). Methods in cultural psychology. In S. Kitayama \& D. Cohen (Eds.), Handbook of cultural psychology. New York: Guilford.
Cohen, D., \& Gunz, A. (2002). As seen by the other . . . Perspectives on the self in the memories and emotional perceptions of Easterners and Westerners. Psychological Science, 13, 55-59.

Cohen, D., \& Hoshino-Browne, E. (2005). Insider and outsider perspectives on the self and social world. In R.M. Sorrentino, D. Cohen, J.M. Olson, \& M.P. Zanna (Eds.), Culture and social behavior (The Ontario Symposium Vol. 10, pp. 49-76). Hillsdale, NJ: Erlbaum.

Cohen, D., Nisbett, R.E., Bowdle, B.F., \& Schwarz, N. (1996). Insult, aggression, and the Southern culture of honor: An "experimental ethnography." Journal of Personality and Social Psychology, 70, 945-960.

Cohen, D., Vandello, J., Puente, S., \& Rantilla, A. (1999). "When you call me that, smile!": How norms for politeness, interaction styles, and aggression work together in southern culture. Social Psychology Quarterly, 62, 257-275.

Cole, M., Gay, J., \& Glick, J. (1968). Some experimental studies of Kpelle quantitative behavior. Psychonomic Monograph Supplements, 2, 173-190.

Cousins, S.D. (1989). Culture and selfhood in Japan and the U.S. Journal of Personality and Social Psychology, 56, 124-131.

Cousins, S.D. (1990). Culture and social phobia in Japan and the United States. Unpublished doctoral dissertation, University of Michigan, Ann Arbor.

Crocker, J., \& Park, L.E. (2004). The costly pursuit of self-esteem. Psychological Bulletin, 130, 392-414.

Cronbach, L.J. (1986). Social inquiry for and by earthlings. In D.W. Fiske \& R.A. Shweder (Eds.), Metatheory in social science: Pluralisms and subjectivities (pp. 83-107). Chicago: University of Chicago Press.

Darwin, C. (1958). The origin of species. New York: New American Library. (Original work published 1859)

Diamond, J. (1997). Guns, germs, and steel: The fates of human societies. New York: Norton.

Diener, E., \& Diener, M. (1995). Cross-cultural correlates of life satisfaction and self-esteem. Journal of Personality and Social Psychology, 68, 653-663.

Diener, E., Diener, M., \& Diener, C. (1995). Factors predicting the subjective well-being of nations. Journal of Personality and Social Psychology, 69, 851-864.

Dobzhansky, T. (1962). Mankind evolving. New York: Bantam.

Doi, T. (1971). The anatomy of dependence. Tokyo: Kodansha.

Edgerton, R. (1971). The individual in cultural adaptation. Los Angeles: University of California Press.

Ekman, P., Sorenson, E.R., \& Friesen, W. (1969). Pancultural elements in facial displays of emotion. Science, 164, 86-88.

Fessler, D. (in press). Steps toward an evolutionary psychology of a culture dependent species. In P. Carruthers, S. Laurence, \& S. Stich (Eds.), Innateness and the structure of the mind (Vol. II). Oxford, England: Oxford University Press.

Gangestad, S.W., Haselton, M.G., \& Buss, D.M. (in press). Evolutionary foundations of cultural variation: Evoked culture and mate preference. Psychological Inquiry.

Gardner, W.L., Gabriel, S., \& Lee, A.Y. (1999). "I" value freedom, but "we" value relationships: Self-construal priming mirrors cultural differences in judgment. Psychological Science, 10, 321326.

Geertz, H. (1959). The vocabulary of emotion: A study of Javanese socialization processes. Psychiatry, 22, 225-237.

Gergen, K.J. (1973). Social psychology as history. Journal of Personality and Social Psychology, 26, 309-320. 
Gordon, P. (2004). Numerical cognition without words: Evidence from Amazonia. Science, 306, 496-499.

Gould, S.J. (1981). The mismeasure of man. New York: Norton.

Greenfield, P.M. (1997). Culture as process: Empirical methods for cultural psychology. In J.W. Berry, Y.H. Poortinga, \& J. Pandey (Eds.), Handbook of cross-cultural psychology (Vol. 1, pp. 301346). Boston: Allyn \& Bacon.

Grossmann, K., Grossmann, K.E., Spangler, S., Suess, G., \& Unzner, L. (1985). Maternal sensitivity and newborn attachment orientation responses as related to quality of attachment in northern Germany. Monographs of the Society for Research in Child Development, 50(1-2, Serial No. 209), 233-256.

Hansen, I.G., \& Norenzayan, A. (in press). Between yang and yin and heaven and hell: Untangling the complex relationship between religion and intolerance. In P. McNamara (Ed.), Where God and science meet: How brain and evolutionary studies alter our understanding of religion. Westport, CT: Praeger.

Heine, S.J. (2001). Self as cultural product: An examination of East Asian and North American selves. Journal of Personality, 69, 881-906.

Heine, S.J. (2005a). Constructing good selves in Japan and North America. In R.M. Sorrentino, D. Cohen, J.M. Olson, \& M.P. Zanna (Eds.), Culture and social behavior (The Ontario Symposium Vol. 10, pp. 115-143). Hillsdale, NJ: Erlbaum.

Heine, S.J. (2005b). Where is the evidence for pancultural self-enhancement? A reply to Sedikides, Gaertner, \& Toguchi. Journal of Personality and Social Psychology, 89, 531-538.

Heine, S.J., Foster, J.A., \& Spina, R. (2005, January). Where birds of a feather might not flock together. Paper presented at the Cultural Psychology Preconference at the annual meeting of the Society for Personality and Social Psychology, New Orleans, LA.

Heine, S.J., \& Hamamura, T. (2006). In search of East Asian self-enhancement. Manuscript submitted for publication.

Heine, S.J., Harihara, M., \& Niiya, Y. (2002). Terror management in Japan. Asian Journal of Social Psychology, 5, 187-196.

Heine, S.J., Kitayama, S., \& Hamamura, T. (in press). Different metaanalyses, different conclusions: A comment on Sedikides, Gaertner, \& Vevea (2005). Asian Journal of Social Psychology.

Heine, S.J., Kitayama, S., Lehman, D.R., Takata, T., Ide, E., Leung, C., \& Matsumoto, H. (2001). Divergent consequences of success and failure in Japan and North America: An investigation of self-improving motivations and malleable selves. Journal of Personality and Social Psychology, 81, 599-615.

Heine, S.J., \& Lehman, D.R. (1997a). The cultural construction of selfenhancement: An examination of group-serving biases. Journal of Personality and Social Psychology, 72, 1268-1283.

Heine, S.J., \& Lehman, D.R. (1997b). Culture, dissonance, and selfaffirmation. Personality and Social Psychology Bulletin, 23, 389400.

Heine, S.J., \& Lehman, D.R. (2004). Move the body, change the self: Acculturative effects on the self-concept. In M. Schaller \& C. Crandall (Eds.), Psychological foundations of culture (pp. 305331). Mahwah, NJ: Erlbaum.

Heine, S.J., Lehman, D.R., Markus, H.R., \& Kitayama, S. (1999). Is there a universal need for positive self-regard? Psychological Review, 106, 766-794.

Heine, S.J., Lehman, D.R., Peng, K., \& Greenholtz, J. (2002). What's wrong with cross-cultural comparisons of subjective Likert scales? The reference-group problem. Journal of Personality and Social Psychology, 82, 903-918.
Heine, S.J., Proulx, T., \& Vohs, K.D. (2006). Meaning maintenance model: On the coherence of social motivations. Personality and Social Psychology Review, 10, 88-110.

Heine, S.J., \& Renshaw, K. (2002). Interjudge agreement, self-enhancement, and liking: Cross-cultural divergences. Personality and Social Psychology Bulletin, 28, 578-587.

Heine, S.J., Takemoto, T., \& Moskalenko, S. (2005). [Objective selfawareness across cultures]. Unpublished raw data.

Hempel, C. (1965). Aspects of scientific explanation and other essays in the philosophy of science. New York: Free Press.

Henrich, J., \& Boyd, R. (1998). The evolution of conformist transmission and between-group differences. Evolution and Human Behavior, 19, 215-242.

Henrich, J., Boyd, R., Bowles, S., Gintis, H., Fehr, E., Camerer, C., McElreath, R., Gurven, M., Hill, K., Barr, A., Ensminger, J., Tracer, D., Marlow, F., Patton, J., Alvard, M., Gil-White, F., \& Henrich, N. (2005). 'Economic man' in cross-cultural perspective: Ethnography and experiments from 15 small-scale societies. Behavioral and Brain Sciences, 28, 795-855.

Imai, M., \& Gentner, D. (1997). A cross-linguistic study of early word meaning: Universal ontology and linguistic influence. Cognition, $62,169-200$.

Iyengar, S.S., \& Lepper, M.R. (1999). Rethinking the value of choice: A cultural perspective on intrinsic motivation. Journal of Personality and Social Psychology, 76, 349-366.

Jablonski, N.G., \& Chaplin, G. (2000). The evolution of human skin coloration. Journal of Human Evolution, 39, 57-106.

Ji, L.J., Peng, K., \& Nisbett, R.E. (2000). Culture, control, and perception of relationships in the environment. Journal of Personality and Social Psychology, 78, 943-955.

Keel, P.K., \& Klump, K.L. (2003). Are eating disorders culture-bound syndromes? Implications for conceptualizing their etiology. Psychological Bulletin, 129, 747-769.

Kim, H.S. (2002). We talk, therefore we think? A cultural analysis of the effect of talking on thinking. Journal of Personality and Social Psychology, 83, 828-842.

Kim, H.S., \& Markus, H.R. (1999). Deviance or uniqueness, harmony or conformity? A cultural analysis. Journal of Personality and Social Psychology, 77, 785-800.

Kitayama, S. (2002). Culture and basic psychological processes-toward a system view of culture: Comment on Oyserman et al. (2002). Psychological Bulletin, 128, 89-96.

Kitayama, S., Markus, H.R., Matsumoto, H., \& Norasakkunkit, V. (1997). Individual and collective processes in the construction of the self: Self-enhancement in the United States and self-criticism in Japan. Journal of Personality and Social Psychology, 72, 12451267.

Kitayama, S., Snibbe, A.C., Markus, H.R., \& Suzuki, T. (2004). Is there any "free" choice? Self and dissonance in two cultures. Psychological Science, 15, 527-533.

Kleinman, A. (1982). Neurasthenia and depression: A study of somatization and culture in China. Culture, Medicine, and Psychiatry, 6, 117-190.

Kleinman, A. (1988). Rethinking psychiatry: From cultural category to personal experience. New York: Free Press.

Knight, N., Varnum, M.E.W., \& Nisbett, R.E. (2005). Culture, class, and categorization. Manuscript submitted for publication.

Kohlberg, L. (1971). From is to ought: How to commit the naturalistic fallacy and get away with it in the study of moral development. In L. Mischel (Ed.), Cognitive development and epistemology (pp. 151-284). New York: Academic Press. 
Koo, M., \& Choi, I. (2005). Becoming a holistic thinker: Training effect of Oriental medicine on reasoning. Personality and Social Psychology Bulletin, 31, 1264-1272.

Kühnen, U., Hannover, B., \& Roeder, U. (2001). Cross-cultural variations in identifying embedded figures: Comparisons from the United States, Germany, Russia, and Malaysia. Journal of CrossCultural Psychology, 32, 365-371.

Kühnen, U., Hannover, B., \& Schubert, B. (2001). The semantic-procedural interface model of the self: The role of self-knowledge for context-dependent versus context-independent modes of thinking. Journal of Personality and Social Psychology, 80, 397-409.

Kühnen, U., \& Oyserman, D. (2002). Thinking about the self influences thinking in general: Cognitive consequences of salient self-concept. Journal of Experimental Social Psychology, 38, 492-499.

Landsteiner, K. (1901). Uber agglutinationserscheinungen normalen menschlichen. Wiener Klinischen Wochenschrift, 14, 1132-1134.

Leary, M.R., Tambor, E.S., Terdal, S.K., \& Downs, D.L. (1995). Selfesteem as an interpersonal monitor: The sociometer hypothesis. Journal of Personality and Social Psychology, 68, 518-530.

Lee, A.Y., Aaker, J.L., \& Gardner, W.L. (2000). The pleasures and pains of distinct self-construals: The role of interdependence in regulatory focus. Journal of Personality and Social Psychology, 78, $1122-1134$.

Lefebvre, L., \& Giraldeau, L.A. (1994). Cultural transmission in pigeons is affected by the number of tutors and bystanders present. Animal Behaviour, 47, 331-337.

Levenson, R.W., Ekman, P., Heider, K., \& Friesen, W.V. (1992). Emotion and autonomic nervous system activity in the Minangkabau of West Sumatra. Journal of Personality and Social Psychology, 62, 972-988.

Levine, R., Sato, S., Hashimoto, T., \& Verma, J. (1995). Love and marriage in eleven cultures. Journal of Cross Cultural Psychology, $26,554-571$.

Levine, R.V., \& Norenzayan, A. (1999). The pace of life in 31 countries. Journal of Cross-Cultural Psychology, 30, 178-205.

Levine, T.R., Bresnahan, M.J., Park, H.S., Lapinski, M.K., Wittenbaum, G.M., Shearman, S.M., Lee, S.Y., Chung, D., \& Ohashi, R. (2003). Self-construal scales lack validity. Human Communication Research, 29, 210-252.

Levinson, S.C. (1997). Language and cognition: The cognitive consequences of spatial description in Guugu Yimithirr. Journal of Linguistic Anthropology, 7, 98-131.

Lucy, J.A., \& Shweder, R.A. (1979). Whorf and his critics: Linguistic and nonlinguistic influences on color memory. American Anthropologist, 81, 581-605.

Lydens, L.A. (1988). A longitudinal study of cross-cultural adoption: Identity development among Asian adoptees at adolescence and early adulthood. Unpublished doctoral dissertation, Northwestern University, Evanston, IL.

Mandel, N. (2003). Shifting selves and decision making: The effects of self construal priming on consumer risk taking. Journal of Consumer Research, 30, 30-40.

Markus, H.R., \& Kitayama, S. (1991). Culture and the self: Implications for cognition, emotion, and motivation. Psychological Review, 98, 224-253.

Masuda, T., \& Nisbett, R.E. (2001). Attending holistically versus analytically: Comparing the context sensitivity of Japanese and Americans. Journal of Personality and Social Psychology, 81, 922-934.

Matsumoto, D. (2006). Culture and cultural worldviews: Do verbal descriptions about culture reflect anything other than verbal descriptions of culture? Culture \& Psychology, 12, 33-62.
Matsumoto, D., \& Yoo, S.H. (2006). Toward a new generation of crosscultural research. Perspectives on Psychological Science, 1, XXXXXX.

McCrae, R.R., Yik, M.S.M., Trapnell, P.D., Bond, M.H., \& Paulhus, D.L. (1998). Interpreting personality profiles across cultures: Bilingual, acculturation, and peer rating studies of Chinese undergraduates. Journal of Personality and Social Psychology, 74, 1041-1055.

Medin, D.L., \& Atran, S. (2004). The native mind: Biological categorization, reasoning and decision making in development and across cultures. Psychological Review, 111, 960-983.

Medin, D.L., Ross, N., Atran, S., Burnett, R.C., \& Block, S.V. (2002). Categorization and reasoning in relation to culture and expertise. In B.H. Ross (Ed.), The psychology of learning and motivation (Vol. 41, pp. 1-41). London: Academic Press.

Miller, J.G., \& Bersoff, D.M. (1992). Culture and moral judgment: How are conflicts between justice and interpersonal responsibilities resolved? Journal of Personality and Social Psychology, 62, 541554.

Miyamoto, Y., Kitayama, S., \& Talhelm, T. (2006, January). A metaanalytic review of cultural differences in cognitive processes. Poster presented at the annual meeting of the Society for Personality and Social Psychology, Palm Springs, CA.

Miyamoto, Y., Nisbett, R.E., \& Masuda, T. (2006). Culture and the physical environment: Holistic versus analytic perceptual affordances. Psychological Science, 17, 113-119.

Morling, B., Kitayama, S., \& Miyamoto, Y. (2002). Cultural practices emphasize influence in the United States and adjustment in Japan. Personality and Social Psychology Bulletin, 28, 311-323.

Morris, M., \& Peng, K. (1994). Culture and cause: American and Chinese attributions for social and physical events. Journal of Personality and Social Psychology, 67, 949-971.

Ngui, P.W. (1969). The koro epidemic in Singapore. Australian New Zealand Journal of Psychiatry, 3, 263-266.

Nisbett, R.E. (2003). The geography of thought. New York: Free Press.

Nisbett, R.E., \& Cohen, D. (1996). Culture of honor: The psychology of violence in the South. Boulder, CO: Westview Press.

Nisbett, R.E., Peng, K., Choi, I., \& Norenzayan, A. (2001). Culture and systems of thought: Holistic versus analytic cognition. Psychological Review, 108, 291-310.

Nisbett, R.E., \& Wilson, T.D. (1977). Telling more than we can know: Verbal reports on mental processes. Psychological Review, 84, 231-259.

Norenzayan, A. (in press). Evolution and transmitted culture. Psychological Inquiry.

Norenzayan, A., \& Heine, S.J. (2005). Psychological universals: What are they and how can we know? Psychological Bulletin, 131, 763784.

Norenzayan, A., Schaller, M., \& Heine, S.J. (in press). Evolution and culture. In M. Schaller, J.A. Simpson, \& D.T. Kenrick (Eds.), Evolution and social psychology. New York: Psychology Press.

Norenzayan, A., Smith, E.E., Kim, B., \& Nisbett, R.E. (2002). Cultural preferences for formal versus intuitive reasoning. Cognitive Science, 26, 653-684.

Obeyesekere, G. (1985). Depression, Buddhism and the work of culture in Sri Lanka. In A. Kleinman \& B. Good (Eds.), Culture and depression (pp. 134-152). Berkeley: University of California Press.

Oishi, S., Diener, E., Napa Scollon, C., \& Biswas-Diener, R. (2004). Cross-situational consistency of affective experiences across cultures. Journal of Personality and Social Psychology, 86, 460472 . 
Oyserman, D., Coon, H.M., \& Kemmelmeier, M. (2002). Rethinking individualism and collectivism: Evaluation of theoretical assumptions and meta-analyses. Psychological Bulletin, 128, 3-72.

Peng, K., \& Nisbett, R.E. (1999). Culture, dialectics, and reasoning about contradiction. American Psychologist, 54, 741-754.

Pica, P., Lerner, C., Izard, V., \& Dehaene, S. (2004). Exact and approximate arithmetic in an Amazonian indigenous group. Science, 306, 499-501.

Plomin, R., Owen, M.J., \& McGuffin, P. (1994). The genetic basis of complex human behaviors. Science, 264, 1733-1739.

Pyszczynski, T., Greenberg, J., \& Solomon, S. (2004). Why do people need self-esteem? A theoretical and empirical review. Psychological Bulletin, 130, 435-468.

Quinones-Vidal, E., Lopez-Garcia, J.J., Penaranda-Ortega, M., \& Tortosa-Gil, F. (2004). The nature of social and personality psychology as reflected in JPSP, 1965-2000. Journal of Personality and Social Psychology, 86, 435-452.

Rendell, L., \& Whitehead, H. (2001). Culture in whales and dolphins. Behavioral and Brain Sciences, 24, 309-382.

Rice, T.W., \& Steele, B. (2004). Subjective well-being and culture across time and space. Journal of Cross-Cultural Psychology, 35, 633-647.

Richerson, P.J., \& Boyd, R. (2005). Not by genes alone. Chicago: University of Chicago Press.

Roberson, D., Davidoff, J., Davies, I., \& Shapiro, L. (2005). Color categories in Himba: Evidence for the cultural relativity hypothesis. Cognitive Psychology, 50, 378-411.

Roberson, D., Davies, I., \& Davidoff, J. (2000). Color categories are not universal: Replications and new evidence from a stone-age culture. Journal of Experimental Psychology: General, 129, 369-398.

Rosaldo, M.Z. (1980). Knowledge and passion: Ilongot notions of self and social life. Cambridge, England: Cambridge University Press.

Rosch Heider, E. (1972). Universals in color naming and memory. Journal of Experimental Psychology, 93, 10-20.

Roy, M.A., Neale, M.C., \& Kendler, K.S. (1995). The genetic epidemiology of self-esteem. British Journal of Psychiatry, 166, 813820.

Rozin, P. (2001). Social psychology and science: Some lessons from Solomon Asch. Personality and Social Psychology Review, 5, 2-14.

Rubel, A.J., O’Nell, C.W., \& Collado, R. (1985). The folk illness called susto. In R.C. Simons \& C.C. Hughes (Eds.), The culture-bound syndromes (pp. 333-350). Dordrecht, The Netherlands: Reidel.

Ryder, A.G., Yang, J., Zhu, X., Yao, S., Yi, J., Bagby, R.M., \& Heine, S.J. (2005). Culture and depression: Are there differences in Chinese and North American symptom presentation? Manuscript submitted for publication.

Sakai, M., Ishikawa, S., Takizawa, M., Sato, H., \& Sakano, Y. (2004). The state of hikikomori from a family's point of view: Statistical survey and the role of psychological intervention. Japanese Journal of Counseling Science, 37, 168-179.

Salmon, W. (1984). Scientific explanation and the causal structure of the world. Princeton, NJ: Princeton University Press.

Sanchez-Burks, J. (2002). Protestant relational ideology and (in)attention to relational work settings. Journal of Personality and Social Psychology, 83, 919-929.

Scarr, S. (1981). Race, social class, and individual differences in IQ. Hillsdale, NJ: Erlbaum.

Schaller, M. (2001). Unintended influence: Social-evolutionary processes in the construction and change of culturally-shared beliefs. In J.P. Forgas \& K.D. Williams (Eds.), Social influence: Direct and indirect processes (pp. 77-93). Philadelphia: Psychology Press.
Schwartz, B. (2004). The paradox of choice: Why more is less. New York: Harper-Collins.

Schwarz, N. (1999). Self-reports: How the questions shape the answers. American Psychologist, 54, 93-105.

Sears, D. (1986). College sophomores in the laboratory: Influences of a narrow data base on social psychology's view of human nature. Journal of Personality and Social Psychology, 51, 515-530.

Sedikides, C., Gaertner, L., \& Vevea, J. (2005). Pancultural self-enhancement reloaded: A meta-analytic reply to Heine (2005). Journal of Personality and Social Psychology, 89, 539-551.

Segall, M.H., Campbell, D.T., \& Herskovits, M.J. (1963). Cultural differences in the perception of geometric illusions. Science, 193, 769-771.

Shweder, R.A. (1990). Cultural psychology: What is it? In J.W. Stigler, R.A. Shweder, \& G. Herdt (Eds.), Cultural psychology: Essays on comparative human development (pp. 1-43). Cambridge, England: Cambridge University Press.

Shweder, R.A. (2000). Moral maps, "first world" conceits, and the new evangelists. In L.E. Harrison \& S.P. Huntington (Eds.), Culture matters: How values shape human progress (pp. 158-176). New York: Basic Books.

Shweder, R.A., Much, N.C., Mahapatra, M., \& Park, L. (1997). The "big three" of morality (autonomy, community, divinity) and the "big three" explanations of suffering. In A.M. Brandt \& P. Rozin (Eds.), Morality and health (pp. 119-169). New York: Routledge.

Singelis, T.M., Bond, M.H., Lai, S.Y., \& Sharkey, W.F. (1999). Unpackaging culture's influence on self-esteem and embarrassability: The role of self-construals. Journal of Cross-Cultural Psychology, 30, 315-331.

Snibbe, A.C., \& Markus, H.R. (2005). You can't always get what you want: Social class, agency, and choice. Journal of Personality and Social Psychology, 88, 703-720.

Spencer, S.J., Zanna, M.P., \& Fong, G.T. (2005). Establishing a causal chain: Why experiments are often more effective than mediational analyses in examining psychological processes. Journal of Personality and Social Psychology, 89, 845-851.

Spencer-Rodgers, J., Peng, K., Wang, L., \& Hou, Y. (2004). Dialectical self-esteem and East-West differences in psychological well-being. Personality and Social Psychology Bulletin, 30, 1416-1432.

Sperber, D. (1996). Explaining culture: A naturalistic approach. Cambridge, MA: Blackwell.

Stevenson, H.W. (1982). Influences of schooling on cognitive development. In D.A. Wagner \& H.W. Stevenson (Eds.), Cultural perspectives on child development (pp. 208-224). San Francisco: W.H. Freeman.

Suh, E.M. (2002). Culture, identity consistency, and subjective wellbeing. Journal of Personality and Social Psychology, 83, 13781391.

Suwanlert, S. (1988). A study of latah in Thailand. Journal of the Psychiatric Association of Thailand, 33(3), 129-133.

Tardif, T. (1996). Nouns are not always learned before verbs: Evidence from Mandarin speakers' early vocabularies. Developmental Psychology, 32, 492-504.

Tomasello, M. (1999). The cultural origins of human cognition. Cambridge, MA: Harvard University Press.

Tomasello, M., Kruger, A.C., \& Ratner, H.H. (1993). Cultural learning. Behavioral and Brain Sciences, 16, 495-552.

Tooby, J., \& Cosmides, L. (1992). The psychological foundations of culture. In J.H. Barkow, L. Cosmides, \& J. Tooby (Eds.), The adapted mind: Evolutionary psychology and the generation of culture (pp. 19-136). New York: Oxford University Press. 
Trafimow, D., Triandis, H.C., \& Goto, S.G. (1991). Some tests of the distinction between the private self and the collective self. Journal of Personality and Social Psychology, 60, 649-655.

Triandis, H.C. (1989). The self and social behavior in differing cultural contexts. Psychological Review, 96, 506-520.

Tseng, W. (2001). Handbook of cultural psychiatry. New York: Academic Press.

Turkheimer, E. (2000). Three laws of behavior genetics and what they mean. Current Directions in Psychological Science, 5, 160-164.

van de Vijver, F.J.R., \& Leung, K. (2000). Methodological issues in psychological research on culture. Journal of Cross-Cultural Psychology, 31, 33-51. van de Vijver, F.J.R., \& Poortinga, Y.H. (2002). Structural equivalence in multilevel research. Journal of Cross-Cultural Psychology, 33, 141-156.

Whiten, A., Goodall, J., McGrew, W.C., Nishida, T., Reynolds, V., Sugiyama, Y., Tutin, C.E.G., Wrangham, R.W., \& Boesch, C. (1999). Cultures in chimpanzees. Nature, 399, 682-685.

Whorf, B.L. (1956). Language, thought, and reality. Cambridge, MA: MIT Press.

Wolsko, C., Park, B., Judd, C.M., \& Wittenbrink, B. (2000). Framing interethnic ideology: Effects of multicultural and color-blind perspectives on judgments of groups and individuals. Journal of Personality and Social Psychology, 78, 635-654.

\section{EPSC 15}




\section{Author Query Form}

\section{Journal PPSC}

Article 15

Dear Author,

During the copy-editing of your paper, the following queries arose. Please respond to these by marking up your proofs with the necessary changes/additions. Please write your answers clearly on the query sheet if there is insufficient space on the page proofs. If returning the proof by fax do not write too close to the paper's edge. Please remember that illegible mark-ups may delay publication.

\begin{tabular}{|c|l|l|}
\hline Query No. & \multicolumn{1}{|c|}{ Description } & Author Response \\
\hline & No Queries & \\
\hline & & \\
\hline & & \\
\hline & & \\
\hline & & \\
\hline & & \\
\hline & & \\
\hline & & \\
\hline & & \\
\hline
\end{tabular}

